\title{
Code Writing of Software Platform or Architecture for in Vitro Diagnostics Device
}

National Cancer Institute

\section{Source}

National Cancer Institute. Code Writing of Software Platform or Architecture for in Vitro

Diagnostics Device. NCI Thesaurus. Code C113080.

The act of writing code for the software of an in vitro diagnostic device. 